\title{
Shape- and Size-Specific Chemistry of Ag Nanostructures in Catalytic Ethylene Epoxidation
}

\author{
Phillip Christopher and Suljo Linic*[a]
}

Catalytic selectivity in the epoxidation of ethylene to form ethylene oxide on alumina-supported silver catalysts is dependent on the geometric structure of catalytically active $\mathrm{Ag}$ particles and reaction conditions. Shape and size controlled synthesis of Ag nanoparticles is used to show that silver nanocubes exhibit higher selectivity than nanowires and nanospheres. For a given shape, larger particles offer improved selectivity. The enhanced selectivity toward ethylene oxide is attributed to the nature of the exposed Ag surface facets; Ag nanocubes and nanowires are dominated by (100) surface facet and Ag nanospheres are dominated by (111). Furthermore, the concentration of undercoordinated surface sites is related to diminished selectivity to ethylene oxide. We demonstrate that a simple model can account for the impact of chemical and physical factors on the reaction selectivity. These observations have also been used to design a selective catalyst for the ethylene epoxidation reaction.

\section{Introduction}

The low selectivity of heterogeneous catalysts has been one of the critical obstacles to the wider use of heterogeneous processes in the commercial production of high value chemicals. ${ }^{[1]}$ The limited selectivity is related to a number of issues, including the lack of predictive theories that guide the discovery of the optimal catalytic site, the dearth of strategies to synthesize the targeted sites at high concentrations, and the difficulties associated with preserving these sites under reaction conditions. ${ }^{[1,2]}$ Advances in the fields of theoretical and synthetic chemistry are beginning to address some of these issues and provide a framework for the identification (based on molecular insight) and synthesis of highly selective uniform catalytic structures with high concentration of targeted surface sites. ${ }^{[2-4]}$

We recently showed that the shape of catalytic silver particles affects selectivity in the epoxidation of ethylene to form ethylene oxide (EO; $\mathrm{C}_{2} \mathrm{H}_{4}+1 / 2 \mathrm{O}_{2} \rightarrow \mathrm{C}_{2} \mathrm{H}_{4} \mathrm{O}$ ) on alumina-supported $\mathrm{Ag}$ catalysts. The selective product in the process is EO, whereas $\mathrm{H}_{2} \mathrm{O}$ and $\mathrm{CO}_{2}$ are undesired byproducts. The studies showed that the selectivity to $\mathrm{EO}$ on $\mathrm{Ag}$ nanowire catalysts was much higher than that on conventional spherical Ag particles with identical external conditions. ${ }^{[4]}$ The enhanced EO selectivity of the nanowire catalysts was attributed to a higher concentration of the $\mathrm{Ag}(100)$ surface facets on nanowires in comparison to spheres. ${ }^{[4 c]}$ Density functional theory (DFT) calculations showed that the $\mathrm{Ag}(100)$ surface facet is inherently more selective towards EO than the Ag(111) facet.

Herein we show that the selectivity to EO in the ethylene epoxidation reaction is further enhanced on uniform supported Ag nanocube catalysts. By comparing the catalytic performance of Ag nanocubes, pentagonal nanowires, and spherical catalytic particles of varying size, we derive a simple model, which can account for the impact of chemical (for example, inherently different outcome of a chemical process on catalytic particles of different shapes), and physical (size of catalytic par- ticles, and the impact of external operating conditions) factors on the reaction selectivity. Our studies show that catalytic particles of controlled size and shape not only represent promising heterogeneous catalysts for selective production of chemicals, but also act as a critical platform to study heterogeneous catalytic processes and to identify crucial factors that impact process selectivity.

\section{Results and Discussion}

To study the effect of size and shape of Ag catalytic particles on the selectivity in ethylene epoxidation, three different sizes of $\mathrm{Ag}$ spherical, nanowire and nanocube structures were synthesized. All particles were synthesized using a modified polyol process, whereby the concentrations of precursor and modifier were varied to control size and shape (see Experimental Section). ${ }^{[(b)]}$ High-resolution transmission electron microscopy (HRTEM) and selected area electron diffraction (SAED) patterns of a representative as-prepared $\mathrm{Ag}$ nanocube and nanowire are shown in Figure 1. The HRTEM micrograph of the nanocube (Figure $1 \mathrm{~b}$ ) was obtained by aligning the electron beam parallel to the (100) plane. The analysis showed that the average distance between the $\mathrm{Ag}$ planes was $0.204 \mathrm{~nm}$, which is consistent with the (100) surface termination. ${ }^{[5 \mathrm{~d}]}$ Figure $1 \mathrm{a}$ shows a HRTEM micrograph of the edge of a pentagonal Ag nanowire obtained with an electron beam aligned parallel to the (111) plane (arrow on Figure $1 \mathrm{a}$, inset). The distance between successive planes was measured as $0.236 \mathrm{~nm}$. The measured plane-to-plane distance is in agreement with previous

\footnotetext{
[a] P. Christopher, Prof. S. Linic

University of Michigan, Department of Chemical Engineering

Ann Arbor, MI 48109-2136 (USA)

Fax: $(+1)$ 734-764-7453

E-mail:linic@umich.edu
} 

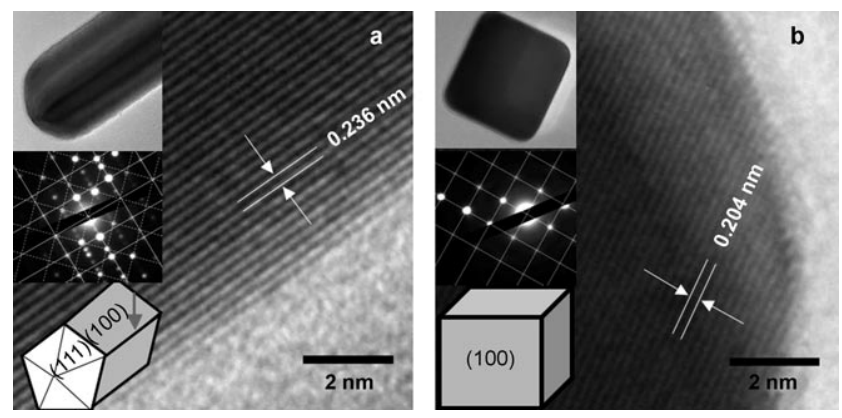

Figure 1. HRTEM images of (a) the Ag nanowire and (b) the Ag nanocube. Insets: Top) zoomed-out TEM images of the nanostructures; middle) selected area electron diffraction patterns used for zone axis identification; bottom) model structures. The arrow in $1 \mathrm{a}$ indicates the beam path aligned parallel to the (111) plane.

HRTEM analysis and DFT calculations, which indicates that the bulk lattice structure of the nanowire is an unstrained face-centered cubic (FCC) structure and that the nanowire is terminated with the (100) plane..$^{[5 b, d]}$ The measured SAED patterns (Figure 1, inset) are also consistent with the proposed (100) surface terminations of the Ag nanowires and nanocubes. ${ }^{[\mathrm{b}]}$ Previous measurements showed that, although the bulk of an $\mathrm{Ag}$ nanowire has an unstrained FCC structure, the nanowires are slightly strained in the regions where two sides of the pentagon meet each other, which might result in a higher concentration of dislocations and undercoordinated sites on the nanowires compared to the nanocubes. ${ }^{[5]}$

Scanning electron microscopy (SEM) and UV/Vis absorbance spectroscopy were used to ensure that the tested catalyst samples contained uniform $\mathrm{Ag}$ particles of the desired shape and size. Figures $2 \mathrm{a}$ and $2 \mathrm{e}$ show representative SEM images of asprepared $90 \mathrm{~nm}$ nanocube and $125 \mathrm{~nm}$ nanowire samples deposited on a $\mathrm{Si}$ wafer. Figures $2 \mathrm{~d}$ and $2 \mathrm{~h}$ show the UV/Vis spectra of the samples. Due to the excitation of surface plasmons, Ag nanoparticles exhibit shape- and size-dependent absorption in the UV/Vis region. The comparison of the measured UV/Vis absorbance spectra with the spectra calculated using the finite-difference time-domain (FDTD) method showed that the respective samples contained $\mathrm{Ag}$ particles of fairly uniform size and shape. Figures $2 b$ and $2 f$ show SEM images of the asprepared $\mathrm{Ag}$ samples deposited on the alumina support. It is clear that anchoring of the Ag nanostructures on alumina does not result in a change in the particle morphology.

To measure the intrinsic selectivity of the catalysts containing Ag nanostructures of different size and shape, we performed reactor studies in which the selectivity to EO was measured at differential reactant conversions (ca. 2-4\% of ethylene was converted in all measurements). We performed the experiments at differential conversions to insure that the loss of EO selectivity due to subsequent reactions of EO was minimal for all samples. The reported selectivities were measured when a steady-state conversion was achieved. All catalysts contained Ag nanostructures deposited on $\alpha$-alumina supports and pretreated using an identical procedure. The EO selectivity is shown in Figure $3 \mathrm{a}$ as a function of the size and shape of $\mathrm{Ag}$
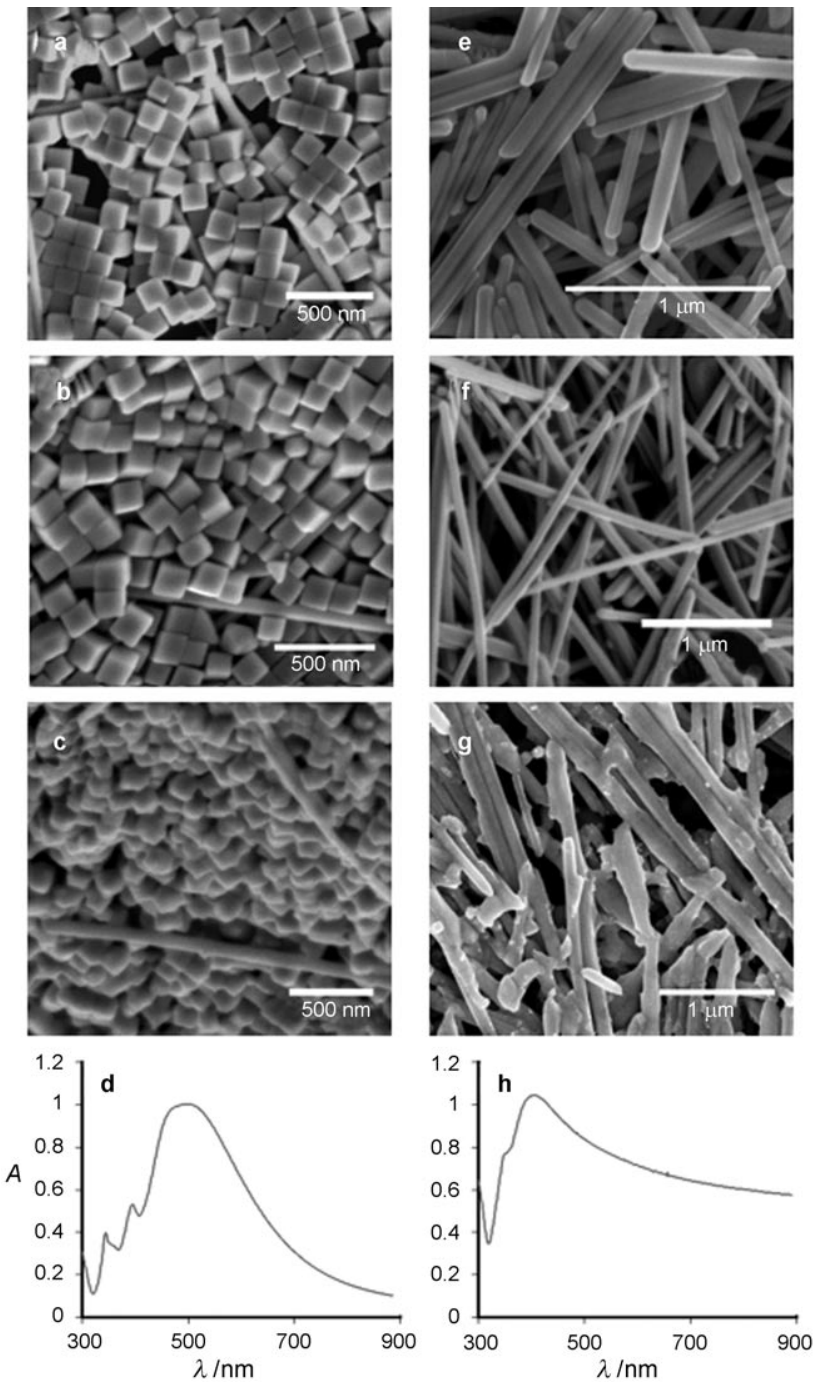

Figure 2. SEM images of $90 \mathrm{~nm}$ nanocubes: a) Deposited on a Si wafer; b) deposited onto the alumina support; c) after $48 \mathrm{~h}$ on stream. d) UV/Vis spectrum of $90 \mathrm{~nm}$ edge length Ag nanocubes in aqueous solution. SEM images of $125 \mathrm{~nm}$ nanowires; e) Deposited on a Si wafer; $f$ ) on alumina support; g) after $48 \mathrm{~h}$ on stream. h) UV/Vis spectrum of $125 \mathrm{~nm}$ diameter $\mathrm{Ag}$ nanowires in aqueous solution.

catalytic particles, as well as the partial pressure of $\mathrm{O}_{2}, p_{\mathrm{O}^{\prime}}$ for six different catalysts measured at $510 \mathrm{~K}$. The partial pressure of ethylene, $p_{\mathrm{Et}}$, was 0.1 for all experiments and the balance was made up by $\mathrm{N}_{2}$. Weight loadings, surface areas (estimated based on idealized particle geometries), and measured rates are reported in Table 1 for the data shown in Figure 3 a.

Three main conclusions can be drawn from Figure $3 \mathrm{a}: 1)$ For a given set of external conditions, the nanocube and nanowire catalysts were significantly more selective than the nanosphere catalysts for all particle sizes, with Ag nanocubes showing better performance than Ag nanowires; 2) for a given particle shape, higher selectivity was obtained on larger particles; 3 ) as the $p_{\mathrm{O}_{2}}$ was increased, leading to a higher oxygen/ethylene ratio, the selectivity to EO also increased. Although we did not test extensively the stability of the catalysts, we recorded a 2$3 \%$ loss in selectivity during the course of a typical lab-scale 

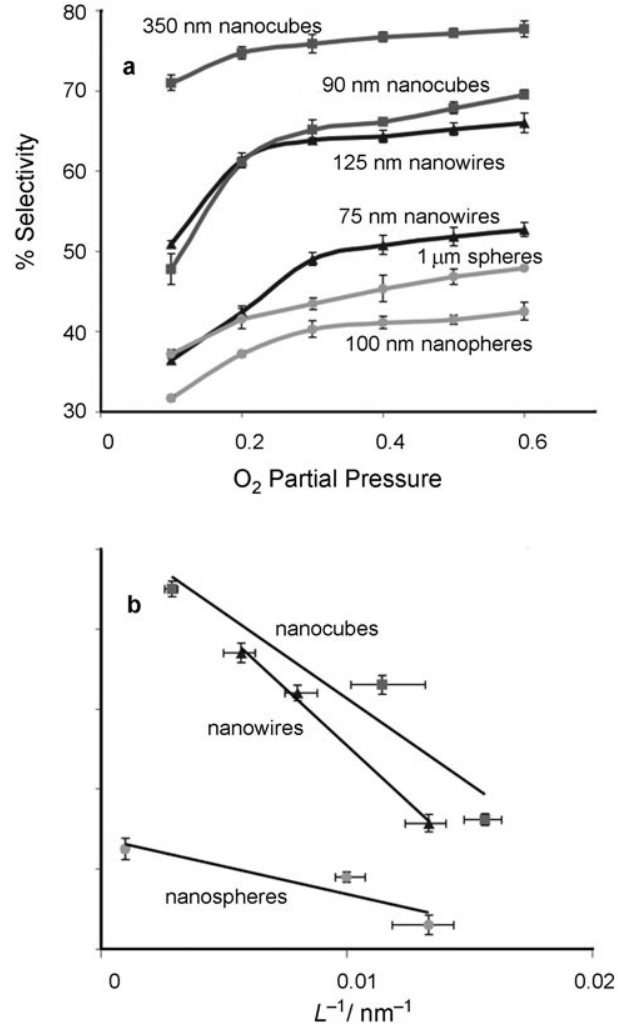

Figure 3. a) Selectivity to EO for Ag nanocubes, nanowires, and nanospheres of different edge lengths and diameters. $T=510 \mathrm{~K}$, conversion $=2-4 \%$. b) Selectivity as a function of $L^{-1}$ for nanocubes, nanowires, and nanospheres of three different sizes. $L^{-1}=$ inverse characteristic length.

\begin{tabular}{|c|c|c|c|}
\hline Catalyst & 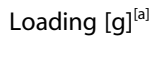 & $\begin{array}{l}\text { Surface area } \mathrm{Ag} \\
{\left[\mathrm{m}^{2} \mathrm{~g}^{-1}\right]^{[\mathrm{b}]}}\end{array}$ & $\begin{array}{l}\text { Rate } \\
{\left[\mathrm{mmol} \mathrm{g}^{-1} \mathrm{~min}^{-1}\right]^{[\mathrm{c}, \mathrm{d}]}}\end{array}$ \\
\hline $90 \mathrm{~nm}$ cubes & 0.027 & 0.029 & $2.3 \times 10^{-3}$ \\
\hline $\begin{array}{l}350 \mathrm{~nm} \\
\text { cubes }\end{array}$ & 0.063 & 0.022 & $9.6 \times 10^{-4}$ \\
\hline $75 \mathrm{~nm}$ wires & 0.012 & 0.060 & $1.2 \times 10^{-2}$ \\
\hline $125 \mathrm{~nm}$ wires & 0.014 & 0.042 & $9.6 \times 10^{-3}$ \\
\hline $\begin{array}{l}100 \mathrm{~nm} \\
\text { spheres }\end{array}$ & 0.009 & 0.06 & $1.9 \times 10^{-2}$ \\
\hline $1 \mu \mathrm{m}$ spheres & 0.12 & 0.069 & $1.5 \times 10^{-3}$ \\
\hline
\end{tabular}

[a] $1.0 \mathrm{~g} \alpha-\mathrm{Al}_{2} \mathrm{O}_{3}$ monolith support used in all experiments; [b] based on weight loading and idealized particle geometries; [c] measured at a $p_{\mathrm{O}_{2}} /$ $p_{\mathrm{Et}}$ ratio of 2.5 ; [d] rate calculated on per gram $\mathrm{Ag}$ basis.

experiment with a reaction time of $48 \mathrm{~h}$. SEM images of the Ag/alumina catalyst samples used on stream for $48 \mathrm{~h}$ (Figures $2 \mathrm{c}$ and $2 \mathrm{~g}$ ) show that, although there is a change in the particle morphology, the shapes of the used Ag nanostructures are still discernible.

The results presented in Figure 3 a show that the shape and size of Ag particles affected the EO selectivity. The discrepancy in the EO selectivity among particles of different shapes can be explained by the inherently higher selectivity of the $\mathrm{Ag}(100)$ facet compared with the $\mathrm{Ag}(111)$ facet. The $\mathrm{Ag}(100)$ facet is present at higher concentrations on the surfaces of Ag nanocubes and nanowires compared to those of spherical particles, which are dominated by the $\mathrm{Ag}(111)$ surface facet. ${ }^{[3 b, c, 5 a, b]}$ We have shown previously using quantum chemical calculations that the higher inherent selectivity of the $\mathrm{Ag}(100)$ facet can be attributed to a preferential ring closure of the surface oxametallacycle-it has been proposed that the oxametallacycle is a critical surface intermediate that governs the selectivity in ethylene epoxidation on $\mathrm{Ag}^{[6]}$ - to form EO on this surface compared to the $\mathrm{Ag}(111)$ surface. ${ }^{[4 c]}$

Figure $3 \mathrm{a}$ also shows that, for a given particle shape, the EO selectivity was also affected by the size of the particles. The effect of particle size on the product distribution in a catalytic process is usually explained in terms of the particle-size-dependent concentration of undercoordinated surface sites (steps and kink sites at particle edges). ${ }^{[7]}$ For a static particle geometry, the relative concentration of undercoordinated surface sites with respect to well-coordinated sites decreases with increasing particle size. For example, if we assume perfect particle geometries, the ratio of undercoordinated surface sites with respect to well-coordinated terrace sites for a given particle shape is inversely proportional to the characteristic length $L$. The characteristic length for the cube is the edge length, whereas for spheres and wires the characteristic length is the diameter. In Figure $3(b)$, we have plotted the EO selectivity measured at differential conversion and a $p_{\mathrm{O}_{2}} / p_{\mathrm{Et}}$ ratio of 2.5 as a function of inverse characteristic lengths $\left(L^{-1}\right)$ for different shapes of $\mathrm{Ag}$ particles. The linear relationships (Figure $3(\mathrm{~b})$ ) imply that undercoordinated sites on Ag particles might be involved in the formation of unselective products. Smaller particles have larger concentrations of undercoordinated sites and therefore the catalysts are less selective. Similar linear relationships between the EO selectivity and the concentration of undercoordinated sites were obtained irrespective of operating conditions. It is worth noting that if the selectivity plot in Figure $3 \mathrm{~b}$ is extrapolated to $L^{-1}=0$ (infinitely large surface facets, i.e., the Ag single crystal surface) the nanowire and nanocube selectivity would reach approximately $80 \%$, whereas the selectivity of spheres would reach approximately $45 \%$. The extrapolated selectivity for spherical particles is consistent with previously measured EO selectivity on the clean $\mathrm{Ag}(111)$ single crystal surface. ${ }^{[8 a, b]}$

Figure $3 \mathrm{a}$ also shows that, for all tested sizes and shapes of $\mathrm{Ag}$ particles, the selectivity increased as $p_{\mathrm{O}_{2}}$ increased. We also found that ethylene conversion increased as a function of $p_{\mathrm{O}_{2}}$ which is not surprising considering that ethylene epoxidation has a positive reaction order with respect to $p_{\mathrm{O}_{2}}{ }^{[8]}$ To investigate the impact of the $p_{\mathrm{O}_{2}}$ on the selectivity to EO, we have plotted differential EO selectivity as a function of $p_{\mathrm{O}_{2}}$ for $\mathrm{Ag}$ nanocubes of 60,90 , and $350 \mathrm{~nm}$ edge lengths (Figure $4(\mathrm{a})$ ). We define the differential EO selectivity as the selectivity to EO associated only with the reaction products produced due to an incremental increase in $p_{\mathrm{O}_{2}}$, as calculated by Equation (1): 


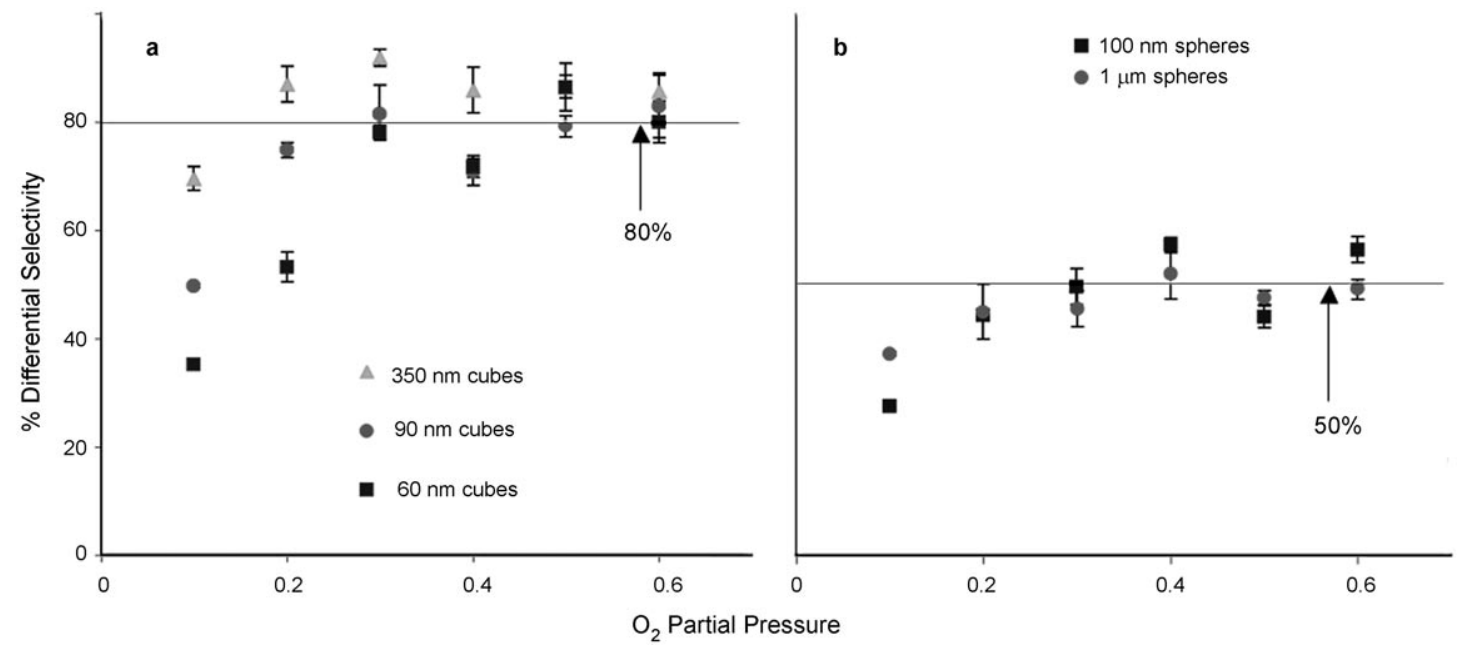

Figure 4. a) Differential selectivity (see text for definition) vs. $\mathrm{O}_{2}$ partial pressure for 60,90 , and $350 \mathrm{~nm}$ cubes. b) Differential selectivity vs. oxygen partial pressure for $100 \mathrm{~nm}$ and $1 \mu \mathrm{m}$ spherical particles

Differential selectivity $=\frac{\Delta p_{\mathrm{EO}}}{\Delta p_{\mathrm{EO}}+1 / 2 \Delta p_{\mathrm{CO}}}=\frac{p_{\mathrm{EO}(n+1)}-p_{\mathrm{EO}(n)}}{p_{\mathrm{Et}(0)}\left[X_{(n+1)}-X_{(n)}\right]}$

where $p_{\mathrm{EO}(n+1)}$ and $p_{\mathrm{EO}(n)}$ are the partial pressures of EO measured at the reactor exit for an experiment $n$, performed with one partial pressure of $\mathrm{O}_{2}$, and an experiment $(n+1)$, performed with a slightly higher partial pressure of $\mathrm{O}_{2}$, respective$l y$, and $p_{\mathrm{Et}(0)}$ is the partial pressure of ethylene fed to the reactor. This partial pressure is identical for experiments $n$ and $(n+$ 1). $X_{(n+1)}$ and $X_{(n)}$ are the conversions of ethylene in experiments $(n+1)$ and $n$ respectively.

Figure 4 a shows differential EO selectivity for three different sizes of cubes as a function of $p_{\mathrm{O}_{2}}$. As $p_{\mathrm{O}_{2}}$ was increased, the differential EO selectivity also increased. The differential selectivity reached a maximum value of about $80 \%$ at $p_{\mathrm{O}_{2}} / p_{\mathrm{Et}}>3$ for all cubes of different sizes, indicating that the effect of particle size was neutralized. The discrepancy in the differential selectivity for nanocubes of different sizes at low $p_{\mathrm{O}_{2}}$ can be understood in terms of a high contribution to the overall rate of chemically active but not highly selective undercoordinated surface sites. As the $p_{\mathrm{O}_{2}} / p_{\mathrm{Et}}$ ratio increased, the contribution of undercoordinated surface sites was saturated and less chemically active sites, such as the terrace sites, became more important, so that different surface sites were populated sequentially as a function of $p_{\mathrm{O}_{2}}{ }^{[8]}$ The differential selectivity accounts only for the selectivity associated with the reaction products produced due to the increase in the reaction rate, in response to the increase in oxygen partial pressure. At high $p_{\mathrm{O}_{2}}$ the differential EO selectivity is basically the selectivity due to well-coordinated surface sites which are, for a given particle shape, chemically identical regardless of the particle size. Similar asymptotic behavior of differential selectivity with respect to $p_{\mathrm{O}_{2}}$ was observed for $\mathrm{Ag}$ spheres (Figure $4 \mathrm{~b}$ ). However, in this case the maximum differential selectivity was about $50 \%$.
The results presented herein show that the impact of the shape and size of catalytic particles on the selectivity of a chemical reaction is manifested through a complex interplay of chemical and physical mechanisms. Our studies show that catalytic particles of different shape and size might exhibit different selectivity, owing to three factors:1) the shape-dependent presence of different surface facets that can activate different chemical pathways; 2) the shape- and size-dependent concentration of undercoordinated sites; 3 ) the shape- and size-specific response to external operating conditions such as temperature and partial pressures of reactants. In the case of ethylene epoxidation on $\mathrm{Ag}$, we found that large particles terminated by the (100) facet with a minimal number of undercoordinated surface sites, operated under external conditions for which the impact of the undercoordinated sites was minimized, should offer optimal selectivity to EO.

We attempted to use these insights to design a catalyst with high selectivity. We synthesized large Ag cubes, with an edge length of $350 \mathrm{~nm}$, mainly terminated with $\mathrm{Ag}(100)$ surface facets. To minimize the impact of undercoordinated sites, we promoted the catalysts with a small amount of chlorine promoter, fed continuously at $2 \mathrm{ppm}$ in the form of vinyl chloride. ${ }^{[9]}$ Vinyl chloride easily decomposes on the $\mathrm{Ag}$ surface forming atomic $\mathrm{Cl}^{\left[{ }^{[\mathrm{bb}]}\right.}$ Our DFT calculations showed that $\mathrm{Cl}$ preferentially adsorbs on the low-coordinated sites of Ag, effectively poisoning these sites. The selectivity as a function of time for this catalyst, operated at $510 \mathrm{~K}$ and $a p_{\mathrm{O}_{2}} / p_{\mathrm{Et}}$ ratio of $3: 1$ (high enough to reach asymptotic differential selectivity) is shown in Figure 5. It is clear that the catalyst exhibits a very high selectivity, $84 \%$, and good stability for the duration of the experiment (up to $15 \mathrm{~h}$ ). The selectivity measured for this fairly simple catalyst, containing only $\mathrm{Ag}$ promoted with $\mathrm{Cl}$, is approaching that achieved by commercial catalysts, which employ $\mathrm{Ag}$ particles promoted with multiple promoters, including $\mathrm{Cl}, \mathrm{Cs}$, and $\mathrm{Re}$, and operated in the presence of sacrificial organic compounds, such as methane and ethane. ${ }^{[10]}$ 


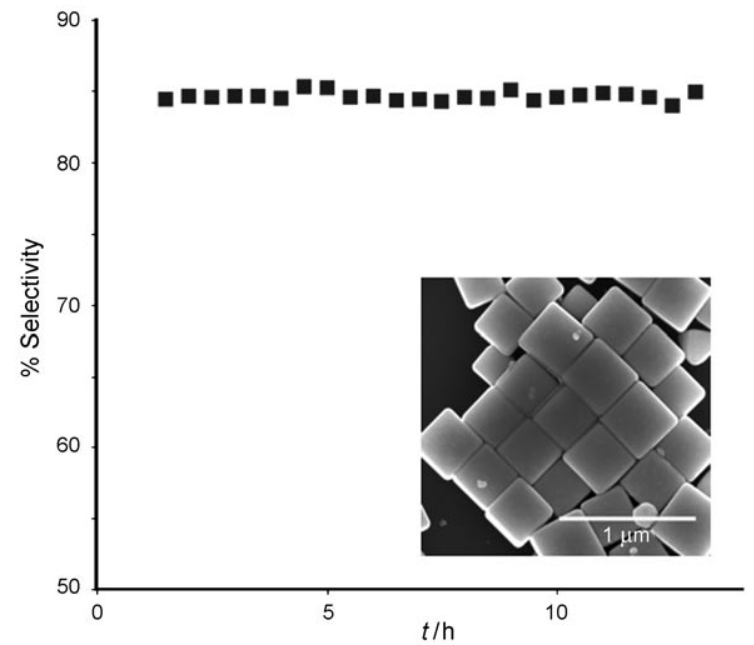

Figure 5. Selectivity as a function of time for $350 \mathrm{~nm}$ nanocubes with $2 \mathrm{ppm}$ vinyl chloride, $p_{\mathrm{O}_{2}} / p_{\mathrm{Et}}=3, T=510 \mathrm{~K}$, steady-state ethylene conversion was $3 \%$.

\section{Conclusions}

In summary, we have shown that the selectivity of Ag catalysts in ethylene epoxidation is governed by the nature of the $\mathrm{Ag}$ surface facets, the abundance of unselective undercoordinated surface sites, and the operating conditions. Our studies have shown that the reaction selectivity can be manipulated by controlling the shape and size of $\mathrm{Ag}$ catalytic particles. We have also demonstrated that catalytic particles of controlled size and shape represent a promising class of materials to study heterogeneous catalytic processes and elucidate the physical and chemical mechanisms that govern selectivity.

\section{Experimental Section}

\section{Nanocube synthesis}

Ethylene glycol [ $5 \mathrm{~mL}$; JT Baker item 9300, low $\mathrm{Cl}(<1 \mathrm{ppm})$ and lower Fe concentrations $(<0.01 \mathrm{ppm})]$ in a $20 \mathrm{~mL}$ vial equipped with a magnetic stir bar (cleaned with piranha solution) was heated at $140-145^{\circ} \mathrm{C}$ for $1 \mathrm{~h}$. A cap was loosely placed atop the vial to allow the evaporation of any contaminant solvent. $\mathrm{HCl}$ ( $30 \mathrm{~mm}$ solution in ethylene glycol, $100 \mu \mathrm{L}$ ) was added to the hot ethylene glycol and the mixture was allowed to mix for 5-10 min. $\mathrm{AgNO}_{3}(0.1 \mathrm{~m}$ solution in ethylene glycol, $3 \mathrm{~mL} ; 99 \%$ purity, Sigma Aldrich cat. no. 209139) and polyvinylpyrrolidone (PVP; $0.15 \mathrm{M}$ solution in ethylene glycol, $3 \mathrm{~mL} ; \mathrm{m} . \mathrm{w} .=55,000$, Sigma Aldrich cat. no. 856568) were added to the heated vial using a syringe pump at a rate of $0.75 \mathrm{~mL} \mathrm{~min}^{-1}$. At this point the cap was loosely placed back onto the vial. This solution was allowed to react at 140 $145^{\circ} \mathrm{C}$ for about $24 \mathrm{~h}$. After this time, the cap on the vial was tightened such that the vial became airtight (the solution is basically colorless at this point). Over the next $2-3 \mathrm{~h}$ a series of color changes were observed resulting in a thick tan/ocher solution, containing cubes of about $60 \mathrm{~nm}$ edge length. By reducing the aliquot of acid to $60 \mu \mathrm{L}$, the cubes were increased in size to $L=90$ $100 \mathrm{~nm}$. Large cubes $(L=350 \mathrm{~nm})$ were synthesized by the same method using ethylene glycol from Sigma Aldrich (cat. no. 324558, $99.8 \%$ anhydrous) and $0.45 \mathrm{M}$ PVP solution. Once again the cap was loosely placed on the vial and the nanocube growth took place over the course of $2-3 \mathrm{~h}$, resulting in a tan/ocher solution. Large cubes $(L=350 \mathrm{~nm})$ were synthesized by the same method of ethylene glycol from Sigma Aldrich (cat. no. 324558, 99.8\% anhydrous) with $0.3 \mathrm{M} \mathrm{AgNO}_{3}$ and $0.45 \mathrm{M}$ PVP solution.

\section{Nanowire synthesis}

The procedure for the synthesis of smaller nanowires $(L=75$ and $125 \mathrm{~nm}$ ) was identical to that for the nanocubes, except that the vial was sealed after $6 \mathrm{~h}$. Large wires $(L=175 \mathrm{~nm})$ were synthesized using ethylene glycol from Sigma Aldrich heated to $140-145^{\circ} \mathrm{C}$, with the cap loosely placed on the vial to allow for evaporation of vapors. $\mathrm{AgNO}_{3}(0.25 \mathrm{M}$ solution in ethylene glycol; $3 \mathrm{~mL}$ ) and PVP $(0.375 \mathrm{M}$ solution in ethylene glycol; $3 \mathrm{~mL})$ were then added at a rate of $0.75 \mathrm{~mL} \mathrm{~min}^{-1}$. Once again, the cap was loosely placed on the vial and the growth took place over the course of $2-3 \mathrm{~h}$ resulting in a tan/ocher solution.

\section{Nanosphere synthesis}

The smaller nanospheres $(L=75 \mathrm{~nm})$ were synthesized using a similar process to the large wire and cube syntheses. Ethylene glycol $(5 \mathrm{~mL})$ from Sigma Aldrich was heated to $160-165^{\circ} \mathrm{C}$. $\mathrm{AgNO}_{3}$ $(0.10 \mathrm{M}$ solution in ethylene glycol; $3 \mathrm{~mL})$ and PVP $(0.6 \mathrm{M}$ solution in ethylene glycol; $3 \mathrm{~mL}$ ) were quickly added to the solution and the vial cap was tightened. Reaction was stopped after $1 \mathrm{~h}$. By increasing the $\mathrm{AgNO}_{3}$ and PVP concentrations by 2.5 times, the sphere size was increased to $L=100 \mathrm{~nm}$. Large spherical particles of $(L=1 \mu \mathrm{m})$ were synthesized by using a wetness impregnation method. A precleaned $\alpha-\mathrm{Al}_{2} \mathrm{O}_{3}$ foam monolith support $(1.0 \mathrm{~g}$, $99.5 \%$, Vesuvius Hi-Tech Ceramics) with a surface area of $0.3 \mathrm{~m}^{2} \mathrm{~g}^{-1}$ was contacted with $\mathrm{AgNO}_{3}$ solution $(0.05 \mathrm{M}$ in ethanol) with a small excess of $\mathrm{Ag}$ compared to the desired loading, and dried in air at $90^{\circ} \mathrm{C}$. The catalyst was reduced in situ, prior to the start of the reaction, in a hydrogen atmosphere at $300^{\circ} \mathrm{C}$ for $3 \mathrm{~h}$.

\section{Catalyst Preparation}

The nanostructured catalysts were prepared using concentrated solutions of nanoparticles in ethanol as the impregnation solution (solutions were concentrated using centrifugation). The $\alpha-\mathrm{Al}_{2} \mathrm{O}_{3}$ foam monolith was then contacted with the impregnation solution and was allowed to dry at $70^{\circ} \mathrm{C}$ in air. The weight loadings were estimated knowing the concentration of nanoparticles in solution and verified by weighing the support before and after impregnation. The polymeric stabilizer and any impurities were removed from the nanoparticles by exposing the catalyst to air for $3 \mathrm{~h}$ at $500 \mathrm{~K}$. X-ray photoelectron spectroscopy and surface-enhanced Raman spectroscopy were utilized to confirm that the catalysts were free of any contaminant that could impact selectivity measurements.

\section{Reactor Studies}

All reactor studies were performed in a horizontally oriented tube reactor operated isothermally at $510 \mathrm{~K}$ and atmospheric pressure. The monolith was secured in a quartz reactor tube using quartz wool. The total inlet flow rate was kept constant at $100 \mathrm{~mL} \mathrm{~min}^{-1}$; gas flow rates were controlled using gas flow controllers and all gases used were the highest purity available. The catalysts were pretreated at $500 \mathrm{~K}$ in $25 \mathrm{~mL} \mathrm{~min}^{-1} \mathrm{O}_{2}$ and $65 \mathrm{~mL} \mathrm{~min}^{-1} \mathrm{~N}_{2}$ for three hours to remove the stabilizer and all impurities. All catalysts were 
allowed to run in $10 \mathrm{~mL} \mathrm{~min}^{-1} \mathrm{O}_{2}$ and $\mathrm{C}_{2} \mathrm{H}_{4}$ and $80 \mathrm{~mL} \mathrm{~min}^{-1} \mathrm{~N}_{2}$ until they reached steady state. The $\mathrm{O}_{2} / \mathrm{C}_{2} \mathrm{H}_{4}$ ratio was then varied by increasing the $\mathrm{O}_{2}$ flow rate and decreasing the $\mathrm{N}_{2}$ carrier gas flow rate while holding the $\mathrm{C}_{2} \mathrm{H}_{4}$ flow rate constant. Product gases were analyzed in line with a Varian gas chromatograph (Varian CP 3800 ) equipped with thermal conductivity (TCD) and flame ionization (FID) detectors. The selectivity was calculated using the FID and the TCD to ensure accurate measurements.

\section{Acknowledgements}

We gratefully acknowledge the support of the US Department of Energy DOE-BES, Division of Chemical Sciences (FG-0205ER15686) and NSF (CTS-CAREER 0543067). SL also acknowledges the DuPont Young Professor grant by the DuPont corporation and the Camille Dreyfus Teacher-Scholar Award from the Camille \& Henry Dreyfus Foundation.

\section{Keywords: epoxidation - heterogeneous catalysis} nanomaterials $\cdot$ selectivity $\cdot$ silver

[1] G. A. Somorjai, R. M. Rioux, Catal. Today 2005, 100, 201.

[2] a) A. T. Bell, Science 2003, 299, 1688; b) J. K. Nørskov, T. Bligaard, J. Rossmeisl, C. H. Christensen, Nat. Chem. 2009, 1, 37.

[3] a) T. S. Ahmadi, Z. L. Wang, C. T. Green, A. Henglein, M. A. El-Sayed, Science 1996, 272, 1924; b) Y Sun, Y Xia, Science 2002, 298, 2176; c) J. Chen, T. Herricks, Y. Xia, Angew. Chem. 2005, 117, 2645; Angew. Chem. Int. Ed. 2005, 44, 2589
[4] a) R. J. Chimentão, I. Kirm, F. Medina, X. Rodriguez, Y. Cesteros, P. Salagre, J. E. Sueiras, Chem. Commun. 2004, 7, 846; b) K. M. Bratlie, H. Lee, K. Komvopoulos, P. Yang, G. A. Somorjai, Nano Lett. 2007, 7, 3097; c) P. Christopher, S. Linic, J. Am. Chem. Soc. 2008, 130, 11264; d) I. Lee, R. Morales, M. A. Albiter, F. Zaera, Proc. Natl. Acad. Sci. USA 2008, 105, 15241; e) E. Nikolla, J. Schwank, S. Linic, J. Am. Chem. Soc. 2009, 131, 2747; f) E. Nikolla, A. Holewinski, J. Schwank, S. Linic, J. Am. Chem. Soc. 2006, 128, 11354.

[5] a) Y. Sun, B. Mayers, T. Herricks, Y. Xia, Nano Lett. 2003, 3, 955; b) J. Reyes-Gasga, J. L. Elechiguerra, C. Lui, A. Camacho-Bragado, J. M. Montejano-Carrizales, M. J. Yacaman, J. Cryst. Growth 2006, 286, 162; C) C. G. Tao, W. G. Cullen, E. D. Williams, S. E. Hunyadi, C. J. Murphy, Surf. Sci. 2007, 601, 4939; d) D. S. Su, T. Jacob, T. W. Hansen, D. Wang, R. Schlögl, B. Freitag, S. Kujawa, Angew. Chem. 2008, 120, 5083; Angew. Chem. Int. Ed. 2008, 47, 5005.

[6] a) S. Linic, M. A. Barteau, J. Am. Chem. Soc. 2003, 125, 4034; b) S. Linic M. A. Barteau, J. Catal. 2003, 214, 200; c) S. Linic, J. Jankowaik, M. A. Barteau, J. Catal. 2004, 224, 489.

[7] a) K. Honkala, A. Hellman, I. N. Remediakis, A. Logadottir, A. Carlsson, S. Dahl, C. H. Christensen, J. K. Norskov, Science 2005, 307, 555; b) G. C. Bond, Surf. Sci. 1985, 156, 966

[8] a) C. T. Campbell, J. Catal. 1985, 94, 436; b) J. G. Serafin, A. C. Liu, S. R. Seyedmonier, J. Mol. Catal. A 1998, 131, 157; c) J. T. Jankowiak, M. A Barteau, J. Catal. 2005, 236, 366

[9] a) C. T. Campbell, J. Catal. 1986, 99, 28; b) D. P. Pursell, M. L. Bocquet J. M. Vohs, H. L. Dai, Surf. Sci. 2003, 522, 90; c) H. Zhang, Q. Fu, Y. Yao, Z. Zheng, T. Ma, D. Tan, X. Bao, Langmuir 2008, 24, 10874.

[10] F. Ullman, Encyclopedia of Industrial Chemistry, 5th, Wiley-VCH, Weinheim, 1985.

Received: September 6, 2009

Published online on November 24, 2009 